\title{
The dynamic relationship between regional corruption and carbon emissions in China
}

\author{
Yuanhua Yang ${ }^{1}\left[\right.$ Xi Yang $^{2} \cdot$ Dengli Tang $^{3}$
}

Received: 24 June 2020 / Accepted: 10 October 2020 / Published online: 22 October 2020

(c) Springer-Verlag GmbH Germany, part of Springer Nature 2020

\begin{abstract}
Does regional corruption exacerbate regional carbon emissions? To answer this, based on the spatial Durbin model, this study empirically examines the impact of regional corruption on carbon emission, using panel data from 30 provinces in China during the period 2002-2017. The results show that: (1) there is an indistinctive $N$-shaped relationship between regional corruption and carbon emissions at the national level. Regional corruption tends to initially aggravate carbon emissions, then contributes to emission reduction, and then finally boosts carbon emissions. However, this effect is not statistically significant. The results suggest that the role of regional corruption on carbon emissions is twofold. Corruption can exacerbate and can also inhibit regional carbon emissions. (2) Pronounced regional heterogeneity exists with regard to the influence of corruption on carbon emissions. Regional corruption and carbon emissions show a significant $N$-shaped dynamic relationship in China's central region, while the relationship is not significant in the eastern and western regions. (3) The impact of regional corruption on carbon emissions varies with time. For 2002-2009, regional corruption did not have a significant effect on carbon emissions. For 2010-2017, the direct effect became significant, and an apparent $N$-shaped relationship formed between regional corruption and carbon emissions. Based on the empirical results, this paper proposes several policy recommendations regarding corruption and carbon governance.
\end{abstract}

\section{Graphic abstract}

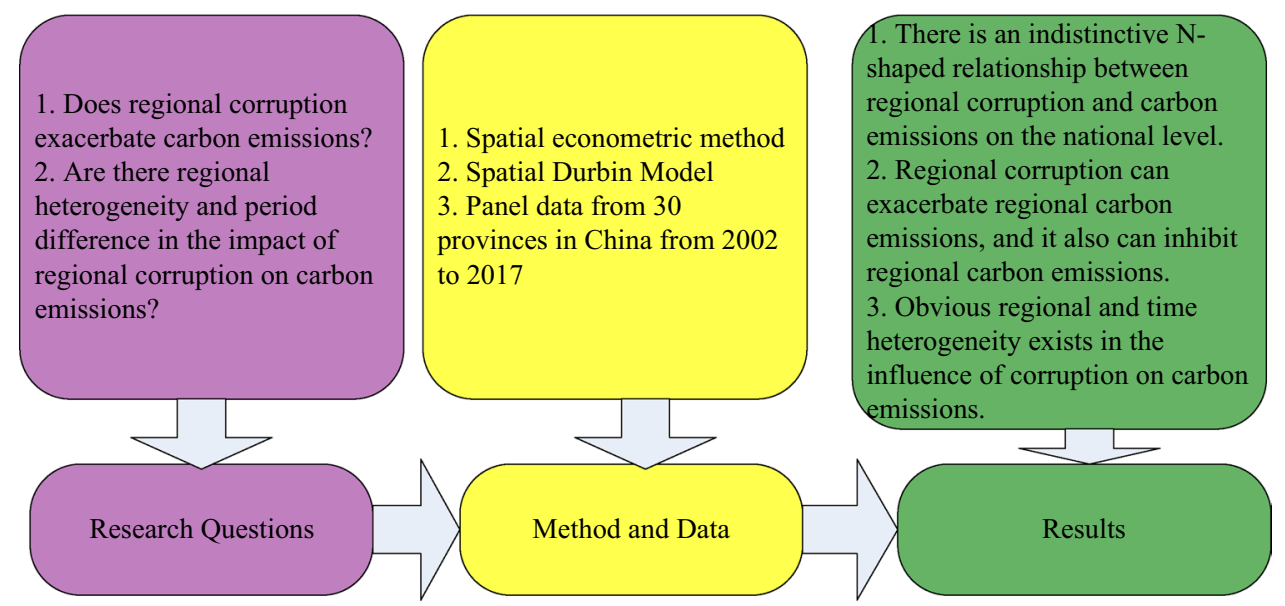

Keywords Regional corruption · Carbon emissions · Spatial Durbin model · Regional heterogeneity

\begin{tabular}{lll} 
& \multicolumn{2}{l}{ Abbreviations } \\
& Ce & Carbon emissions \\
& Rc $\quad$ Regional corruption \\
\hline Yuanhua Yang & Er & Environmental regulation \\
260782245@qq.com & GDP & Gross domestic product \\
Extended author information available on the last page of the article & FDI & Foreign direct investment
\end{tabular}


Is Industrial structure

laec Labor-average energy consumption

Isde Industrial smoke and dust emissions

\section{List of symbols}

$Y \quad$ Dependent variable

$X \quad$ Explanatory variable

$W \quad$ Spatial weight matrix

$\delta \quad$ The slope coefficients

$\theta \quad$ The slope coefficients

$\beta \quad$ The slope coefficients

$\mu_{\mathrm{i}} \quad$ The area effect

$\lambda_{\mathrm{t}} \quad$ The time effect

$\varepsilon_{\text {it }} \quad$ The random disturbance term

$\alpha \quad$ The slope coefficients

$\sigma \quad$ The slope coefficients

$i \quad$ The provinces $i$

$j \quad$ The provinces $j$

$t \quad$ One of the years

$N \quad$ Total number of provinces

$C_{\text {it }} \quad$ The total amount of carbon dioxide emissions of province $i$ in year $t$

$E_{\text {irt }} \quad$ The consumption of energy $r$ in year- $t$ of province $i$

$\eta_{\mathrm{r}} \quad$ The carbon emission coefficient of the $r$-th type of energy

\section{Introduction}

Since economic reforms and opening up have been initiated, China has made tremendous achievements in economic and social development. However, China has also been facing pressures from severe corruption and environmental pollution. Corruption is defined as "the abuse of public power for private gain" (World Bank 1997). Corruption is not unique to any one country or region but is a widespread phenomenon in all countries of the world (Chen 2011). According to statistics released by the Transparency International Corporation, China received 36 points in the Corruption Perception Index in 2014, ranking 100th out of 175 countries, which suggests that corruption is prevalent and sever (Yu 2019). Simultaneously, according to the global environmental performance rankings, China's Environmental Performance Index was 65.1 points in 2016, which is 109th among 180 countries. This indicates that the country's environmental performance is relatively low and that the environmental challenges are serious (Wang et al. 2018; Kazerouni et al. 2019). As measures to mitigate climate change and reduce emissions become more urgent, China faces the twin pressures of corruption and carbon emissions governance (Akhbari and Nejati 2019).

Will regional corruption directly exacerbate carbon emissions? Is there significant spatial spillover effect on the impact of corruption on carbon emissions? If so, does the impact vary by region and time period? Several researchers have explored the impact of corruption on environmental quality, but few have directly focused on analyzing the effect of corruption on carbon emissions in China (Yu 2019). Furthermore, when examining the influence of corruption on environmental pollution, few in the existing literature has considered the spatial spillover effect of corruption in carbon emissions, and few have covered regional heterogeneity and time differences in the relationship between the two. Hence, based on the analysis of the spatial spillover effect of corruption and carbon emissions, this study adopted the spatial Durbin model to examine the impact of corruption on carbon emissions using panel data of 30 provinces in China. This study also explores the regional heterogeneity and period differences of this impact.

\section{Literature review}

The impact of regional corruption on regional carbon emissions is an important manifestation of the impact of corruption on regional environmental quality. With the weakening of regulatory and monitoring institutions, corruption causes environmental degradation (Wang et al. 2018). Many scholars have proved this view. Based on the Environmental Kuznets Curve (EKC) hypothesis, Cole (2007) used data from 94 countries from 1987 to 2000 to analyze the impact of corruption on pollution emissions and found that corruption has led to the increase of per capita sulfur dioxide and carbon dioxide emissions (Cole 2007). Goel et al. (2013) analyzed the impacts of corruption and the shadow economy on the level of pollution emissions by using a sample of 100 countries in Middle East and North Africa (MENA) from 2004 to 2007. Their study reveals that low emissions records often appear in countries with a low level of corruption and shadow economies (Goel et al. 2013). Hassaballa (2015) employed a fixed-benefit panel model to investigate the impacts of corruption on per capita carbon dioxide emissions, taking the Middle East and North Africa region during 1996-2013 as sample. The results of the study indicate that corruption is a significant factor affecting carbon dioxide emissions (Hassaballa 2015). Oliva (2015) used Mexico as an example to explore the impact of corruption on automobile carbon dioxide emissions and found that corruption affects automobile carbon dioxide emissions (Oliva 2015). Sahli and Ben Rejeb (2015) found that there is a positive direct impact of corruption on per capita emissions in 21 countries of the MENA region (Sahli and Ben Rejeb 2015). According to Zhang et al. (2016), on the whole, regional corruption has exacerbated regional $\mathrm{CO}_{2}$ emissions in China, although there are differences in direct and indirect effects of them (Zhang et al. 2016). Liao et al. (2016) showed that 
China's anti-corruption efforts in recent years have indeed reduced sulfur dioxide emissions (Liao et al. 2016). Through employing both linear and non-linear approaches on the province-level panel data, $\mathrm{Li}$ et al. (2017) indicate that there are significant regional differences in the impact of regional corruption on $\mathrm{CO}_{2}$ ( $\mathrm{Li}$ et al. 2017). Based on the panel data of South Africa, Brazil, Russia, India, and China (BRICS) from 1996 to 2015, Wang et al. (2018) infer that regulating the effect of corruption is crucial between economic growth and carbon dioxide emissions, and control of corruption reduces carbon emissions by applying a partial least square regression model (Wang et al. 2018). Through the Generalized method of moments (GMM) method, Masron and Subramaniam (2018) found that corruption increases environmental pollution in 64 developing countries (Masron and Subramaniam 2018). Ben Jabeur and Sghaier (2018) used the partial least square method and structural equation modeling (PLS-SEM) approach to show corruption moderates economic growth and worsen the environmental quality in the MENA region (Ben Jabeur and Sghaier 2018). Wang et al. (2019a, b) suggest that under the influence of the invisible economy, corruption further increases the emission of pollutants in China (Wang et al. 2019a, b). Akhbari and Nejati (2019) believe that there is a threshold effect between corruption and $\mathrm{CO}_{2}$ emissions in 161 countries of the world (Akhbari and Nejati 2019). According to Rodriguez and Galindo Villardon (2019), lower corruption levels result in higher environmental performance index (Rodriguez and Galindo Villardon 2019).

In China, some scholars have explored the impact of corruption on environmental quality. Lu and Zhang (2011) point out that strengthening the government's corruption governance helps improve the efficiency of carbon reduction governance in China (Lu and Zhang 2011). By using threshold panel regression and cross-section cross-term estimation, Li and Liu (2013a, b) investigated that regional corruption directly contributes to the increase of pollution emissions in various regions of China ( $\mathrm{Li}$ and Liu 2013a). Corruption can either directly aggravate environmental pollution by reducing environmental regulations or distorting environmental policies, or indirectly reduce or increase environmental pollution by reducing income levels ( $\mathrm{Li}$ and Liu 2013b). Jin and Wu (2014) discovered that corruption could negatively affect environmental pollution by weakening economic growth (Jin and Wu 2014). Based on Chinese provincial dynamic panel data from 1992 to 2009, Que and Lv (2015) utilized systematic generalized moment estimation methods and found corruption to exacerbate not only environmental pollution but also the environmental pollution effect of foreign trade (Que and Lv 2015). Corruption has led to a "bottom-to-bottom race" among local governments, which has worsened the environment in
China (Liao and Xia 2015). Chen (2016) adopted dynamic panel regression technology to investigate the impacts of corruption and foreign direct investment (FDI) on environmental quality. The study showed that corruption not only inhibits economic growth and causes social injustice, but it also brings about environmental problems by attracting a large number of low-quality FDI (Chen 2016). Yu (2019) employed a systematic GMM method to investigate the impacts of corruption and informal economic activities on China's environmental quality. The results reveal that corruption aggravates environmental pollution by increasing the size of the informal economy (Yu 2019).

It can be seen that some scholars have carried out beneficial explorations on the impact of corruption on the regional environment. Most studies have shown that corruption deteriorates the regional environmental quality and exacerbates regional pollution emissions (Wang et al. 2018). First, the existing literature has mainly focused on corruption and environmental quality. Few have made direct reference to the effect of regional corruption on carbon emissions. Second, when analyzing the corruptionenvironment link, the primary consideration has been the linear relationship, while the non-linear and dynamic relationship between the two is rarely covered. Third, with respect to the regional heterogeneity and period difference, most studies focus more on heterogeneity across different countries. Few have compared regions inside one country, which is of great importance and necessity for analyzing the governance of regional corruption and carbon emissions. Finally, in terms of research methods, present studies have been conducted mostly using traditional econometric methods, failing to consider the spatial spillover characteristics of corruption and carbon emissions, as well as the complex associations. Carbon emission is a nonlocal pollution problem with spatial spillovers and correlation characteristics. Therefore, this study contributes to the following aspects. For the research method, this study introduces spatial econometrics techniques and considers spatial spillover characteristics of regional corruption and carbon emissions. When studying the impact of corruption on carbon emission, with the help of the spatial Durbin model, this study also explores the total, indirect, and direct effects of regional corruption on carbon emissions. Also, there is a dynamic non-linear relationship between corruption and carbon emissions, with corruption not significantly contributing to regional carbon emissions. This coincides with the continued improvements in the environment and corruption in the context of China's economic development. Moreover, compared to the existing studies, this study conducts more in-depth research on the regional heterogeneity and period difference in the impact of corruption on carbon emissions. 


\section{Research design}

\section{Model building}

In order to consider the spatial correlation between variables, this study chooses a spatial econometric model to analyze the impact of corruption on regional carbon emissions. Anselin (1995) proposed the classic spatial lag model (SLM) and spatial error model (SEM), and then James and
Based on Hassaballa's (2015) model on the relationship between corruption and carbon dioxide emissions reduction, a spatial econometric model was constructed for the impact of corruption on carbon emissions (Hassaballa 2015). In order to investigate the non-linear relationship between the two, the quadratic and cubic terms of regional corruption have been added, along with the lagging term of one period of carbon emissions. The spatial Durbin model for the impact of corruption on carbon emissions is as follows:

$$
\begin{aligned}
\operatorname{lnc} \mathrm{e}_{\mathrm{it}}= & \delta \sum_{j=1}^{N} w_{i j} \ln \mathrm{ce}_{j t}+\alpha_{1} \ln \mathrm{rc}_{\mathrm{it}}+\sigma_{1} \sum_{j=1}^{N} w_{i j} \ln \mathrm{rc}_{j t}+\alpha_{2} \ln ^{2} \mathrm{rc}_{\mathrm{it}} \\
& +\sigma_{2} \sum_{j=1}^{N} w_{i j} \ln ^{2} \mathrm{rc}_{j t}+\alpha_{3} \ln ^{3} \mathrm{rc}_{\mathrm{it}}+\sigma_{3} \sum_{j=1}^{N} w_{i j} \ln ^{3} \mathrm{rc}_{j t}+\gamma_{1} X_{\mathrm{it}}+\mu_{t}+\lambda_{t}+\varepsilon_{\mathrm{it}}
\end{aligned}
$$

Kelly extended the SLM model and put forward the Spatial Durbin Model (SDM), which includes the lag term of both the explanatory and explained variables (Anselin 1995; Kelly and Vollebergh 2012). With the existence of the spatial lag term, the regression coefficients do not merely reflect the effect of explanatory variables on the explained variables. LeSage and Pace (2010) divided the total effect into direct effect and indirect effect in order to better describe the spatial interactions and spillover effect between variables (Lesage and Pace 2010). The SDM model conducts decomposition on the coefficients, where the direct effect represents the average impact of the explanatory variables on the explained variables in the region, the indirect effect denotes the average impact of the explained variables on surrounding areas, and the total effect represents the average impact on all regions (Lesage and Pace 2010). The basic form of the SDM model is as follows:

$Y_{\mathrm{it}}=\delta \sum_{j=1}^{N} w_{i j} y_{j t}+\beta x_{\mathrm{it}}+\theta \sum_{j=1}^{N} w_{i j} X_{j t}+\mu_{i}+\lambda_{t}+\varepsilon_{\mathrm{it}}$

where $Y$ is the explained variable; $X$ is the explanatory variable set; $w$ is the spatial weight matrix; $\delta \sum_{i=1}^{N} w_{i j} y_{i j}$ represents the spatial lag term of the explained variable; $\theta \sum_{j=1}^{N} w_{i j} x_{i j}$ is the spatial lag term of the explanatory variable; $\mu_{i}$ is the area effect; $\lambda_{t}$ is the time effect; and, $\varepsilon_{\mathrm{it}}$ is the random disturbance term. If $\theta=0$, Model (1) would degrade into the spatial panel lag model; if $\theta+\delta \beta=0$, the model would degrade into the spatial panel error model. This means that the spatial panel Durbin model is the more general form. In this study, the adjacency matrix is adopted, and $w$ can be expressed by the following formula:

$W=\left[\begin{array}{ccc}w_{11} & \cdots & w_{1 n} \\ \vdots & \cdots & \vdots \\ w_{n 1} & \cdots & w_{n n}\end{array}\right]$ where $\operatorname{lnce}_{\mathrm{it}}, \operatorname{lnr}_{\mathrm{it}}$, and $X$ denote the amount of carbon dioxide emissions, the corruption level, and the set of control variables, respectively. The control variables include economic development level, FDI, industrial structure, energy consumption per labor, environmental regulation, and industrial smoke and dust emissions. Economic development level and the degree of economic openness have crucial effects on environmental quality and carbon emissions. Regions with high levels of economic development and economic openness tend to attach more importance to environmental protection and control of regional carbon emissions (Freckleton et al. 2012; Masron and Subramaniam 2018). However, there is also evidence suggesting that areas with a higher level of economic development and higher economic openness suffer from more severe environmental pollution (Liao et al. 2016). The energy consumption of a region depends on the industrial structure of the region. Regions with a high proportion of secondary industries often have high energy consumption and heavy carbon emissions (Qin et al. 2016; Yu 2019). Regional environmental regulation has a direct impact on regional carbon emissions (Yang et al. 2020). In addition, the greater the emissions of industrial solid wastes such as smoke and dust, the more the carbon emissions produced.

\section{Measure of variables}

According to the calculation method provided by the Intergovernmental Panel on Climate Change (IPCC) and the 2006 IPCC Guidelines for National Greenhouse Gas Inventories, the calculation of carbon dioxide includes three steps. First, the total consumption of each kind of energy consumption for each province is calculated separately. In this study, eight kinds of energy consumption were included, namely coal, coke, crude oil, gasoline, kerosene, diesel, fuel oil, and natural gas. In order to unify the units, we carried out a unit conversion for the various energy consumption aggregates. The 
Table 1 Descriptive statistics of variables

\begin{tabular}{|c|c|c|c|c|c|}
\hline Variables & Definition & Minimum & Maximum & Mean & SD \\
\hline ce & Carbon emissions & 6.0369 & 10.5274 & 8.7680 & 0.8024 \\
\hline $\mathrm{rc}$ & REGIONAL corruption & 4.8363 & 8.2488 & 6.8591 & 0.7540 \\
\hline $\mathrm{rc}^{2}$ & The square of regional corruption & 23.3896 & 68.0425 & 47.6151 & 9.8887 \\
\hline $\mathrm{rc}^{3}$ & The cube of regional corruption & 113.1188 & 561.2687 & 334.0233 & 98.7534 \\
\hline er & Environmental regulation & 0.0953 & 7.2557 & 4.6522 & 1.1573 \\
\hline gdp & Gross domestic product & 8.0886 & 11.7679 & 10.1515 & 0.7747 \\
\hline fdi & Foreign direct investment & -0.0037 & 7.7219 & 5.0232 & 1.6676 \\
\hline is & Industrial structure & 2.4713 & 4.0817 & 3.6351 & 0.2638 \\
\hline laec & Labor-average energy consumption & 1.6812 & 4.5613 & 3.0278 & 0.5979 \\
\hline isde & Industrial smoke and dust emissions & -0.4276 & 5.1917 & 3.1189 & 1.0039 \\
\hline
\end{tabular}

conversion method had been provided by the China Energy Statistical Yearbook (2008). Second, the carbon emissions of each kind of energy consumption are converted according to the carbon conversion coefficients published by the China Energy Statistical Yearbook in 2008. Finally, the carbon emissions for the eight kinds of energy consumption are summed to get the final total carbon emissions of each province (Wu 2015). The calculation method is as follows:

$C_{\mathrm{i}, \mathrm{t}}=\sum\left(E_{\mathrm{irt}} \cdot \eta_{\mathrm{r}}\right)$

where $C_{\mathrm{it}}$ is the total amount of carbon dioxide emissions of province $i$ in year $t ; E_{\text {irt }}$ denotes the consumption of energy $r$ in year- $t$ of province $i$, and $\eta_{\mathrm{r}}$ is the carbon emission coefficient of the $r$-th type of energy.

Corruption also undermines social equity and social justice, distorts legal rules and weakens institutional foundations, and is considered to be the greatest obstacle to socio-economic development (Persson et al. 2013). Corruption has certain hidden characteristics, and how to effectively measure corruption has been the focus of numerous quantitative research. Currently, there are two main methods for establishing corruption indices: subjective evaluation and objective measurement. The subjective evaluation method generally involves the use of questionnaire surveys to the population, enterprises, or experts, and is then followed by an evaluation of the corruption index. Corruption Perceptions Index (CPI) published by Transparency International is one of the more representative indicators. Objective measures of corruption use indicators, such as the number of corruption cases filed, the number of persons filing cases, and the amount of money involved. The number of corruption cases filed by provincial prosecutors, documented by the China Procuratorial Yearbook, was used for the level of regional corruption. Relevant local legal yearbooks, economic yearbooks, and work reports were also used to supplement missing data (Liu and Feng 2011; Liao et al. 2016; Yu 2019).
Third, environmental regulation was measured by the total amount of investment in pollution governance (Yang et al. 2018). The level of economic development was quantified through the gross domestic product (GDP) per capita, while FDI was measured using the actual level of foreign investment in various regions (Masron and Subramaniam 2018). The proportion of the secondary industry in all industries was used as the metric for industrial structure (Liu and Feng 2011; Freckleton et al. 2012). Labor-average energy consumption was measured by the ratio of the total amount of industrial energy consumption to industrial employment figures (Qin et al. 2016). The measurement of industrial smoke and dust emissions was expressed by the annual total amount (Liu and Xu 2017).

\section{Data sources}

Due to missing data for Tibet, 30 provinces in China from 2002 to 2017 are considered as samples. Corruption data were derived from the China Inspection Yearbook. Missing and incomplete data for 2007 were obtained by sorting out political and legal statistics for each province. Environmental regulation data came from the China Environmental Statistics Yearbook, while the rest of the data were sourced from China Statistical Yearbook of Science and Technology and China Statistical Yearbook. Gaps in the data were filled by the mean method. The data were logarithmically processed, and Table 1 shows the definition and descriptive statistics of variables.

\section{Results}

\section{Spatial correlation analysis}

Tables 2 and 3 provide the Moran's I-values of regional corruption (RC) and carbon emissions (CE) in 30 provinces in China from 2002 to 2017, respectively. According to the results, the average Moran's I-values of regional 
Table 2 Moran's $I$-values of regional corruption in China from 2002 to 2017

\begin{tabular}{llllll}
\hline Years & Moran's $I$ & $E(I)$ & $\mathrm{Sd}(I)$ & $P$-values & $Z$-value \\
\hline 2002 & 0.2331 & -0.0345 & 0.1212 & 0.0260 & 2.2829 \\
2003 & 0.1817 & -0.0345 & 0.1125 & 0.0640 & 1.8008 \\
2004 & 0.2119 & -0.0345 & 0.1151 & 0.0020 & 2.0591 \\
2005 & 0.2302 & -0.0345 & 0.1089 & 0.0100 & 2.3317 \\
2006 & 0.2078 & -0.0345 & 0.1161 & 0.0300 & 2.1425 \\
2007 & 0.2601 & -0.0345 & 0.1199 & 0.0240 & 2.5939 \\
2008 & 0.2596 & -0.0345 & 0.1195 & 0.0180 & 2.4976 \\
2009 & 0.2186 & -0.0345 & 0.1157 & 0.0220 & 2.1715 \\
2010 & 0.2500 & -0.0345 & 0.1149 & 0.0120 & 2.4055 \\
2011 & 0.2203 & -0.0345 & 0.1181 & 0.0320 & 2.0698 \\
2012 & 0.2259 & -0.0345 & 0.1115 & 0.0100 & 2.4003 \\
2013 & 0.2310 & -0.0345 & 0.1185 & 0.0240 & 2.2568 \\
2014 & 0.2209 & -0.0345 & 0.1131 & 0.0200 & 2.2173 \\
2015 & 0.2413 & -0.0345 & 0.1149 & 0.01600 & 2.4235 \\
2016 & 0.2422 & -0.0345 & 0.1171 & 0.2000 & 2.3579 \\
2017 & 0.1720 & -0.0345 & 0.1110 & 0.0440 & 1.8470 \\
\hline
\end{tabular}

Table 3 Moran's $I$-values of carbon emissions in China from 2002 to 2017

\begin{tabular}{llllll}
\hline Years & Moran's $I$ & $E(I)$ & $\mathrm{Sd}(I)$ & $P$-values & $Z$-value \\
\hline 2002 & 0.2507 & -0.0345 & 0.1119 & 0.0120 & 2.5529 \\
2003 & 0.2241 & -0.0345 & 0.1193 & 0.0260 & 2.1234 \\
2004 & 0.2586 & -0.0345 & 0.1131 & 0.0180 & 2.5465 \\
2005 & 0.2852 & -0.0345 & 0.1133 & 0.0040 & 2.8257 \\
2006 & 0.2741 & -0.0345 & 0.1205 & 0.0040 & 2.5170 \\
2007 & 0.2746 & -0.0345 & 0.1102 & 0.0080 & 2.7492 \\
2008 & 0.2835 & -0.0345 & 0.1122 & 0.0060 & 2.8564 \\
2009 & 0.2618 & -0.0345 & 0.1196 & 0.0220 & 2.4510 \\
2010 & 0.2602 & -0.0345 & 0.1124 & 0.0200 & 2.3787 \\
2011 & 0.2652 & -0.0345 & 0.1136 & 0.0080 & 2.6351 \\
2012 & 0.2475 & -0.0345 & 0.1158 & 0.0140 & 2.3953 \\
2013 & 0.2515 & -0.0345 & 0.1125 & 0.0160 & 2.4909 \\
2014 & 0.1968 & -0.0345 & 0.1148 & 0.0360 & 1.9748 \\
2015 & 0.2266 & -0.0345 & 0.1124 & 0.0260 & 2.1997 \\
2016 & 0.2081 & -0.0345 & 0.1095 & 0.0260 & 2.2445 \\
2017 & 0.2029 & -0.0345 & 0.1152 & 0.0420 & 1.9398 \\
\hline
\end{tabular}

corruption and carbon emissions from 2002 to 2017 are 0.2254 and 0.2482 , respectively, both of which pass the significance test at the 5\% level. This indicates a clear spatial dependence and space spillover characteristics in both regional corruption and carbon emissions in China. From Fig. 1 showing the trend of the Moran's values for regional corruption and carbon emissions, the overall trend tends to be stable with individual values fluctuating from 0.15 to 0.30 . Figure 2 shows Moran scatterplots of regional corruption and carbon emissions in China. For the years 2002, 2007, 2012, and 2017, more than half of the Moran scatterplots are distributed in the first and third quadrants, which implies spatial positive correlation characteristics for the two. This is consistent with the findings of $\mathrm{Wu}$ (2015) and Yang et al. (2018). Both of them have significant spatial spillover effects, laying the foundation for the empirical study of the spatial Durbin model selected in this paper.

\section{Impact of regional corruption on carbon emissions}

Before the empirical analysis, we compared the SDM, SLM, and SEM models, and the results are shown in Table 4. The p-values of the Wald spatial lag and LR spatial lag tests which are less than 0.05 explain that the SDM model is better in explanation from Table 4. Therefore, for this study, we selected the SDM model in conducting the spatial econometrics analysis (Shao et al. 2019).

Table 5 reports the spatial panel regression results of regional corruption on carbon emissions. By comparing the Adjusted $\mathrm{R}^{2}$ and $\mathrm{Log}$-likelihood values of the no fixed effect (NFE), space fixed effect (SFE), time fixed effect (TFE), and space-time fixed effect (STFE) models in Table 5, the no fixed effect model was found to be the optimal interpretation model. Therefore, the subsequent analyses were conducted using the no fixed effect model.

In Table 5, the estimated coefficient of $\rho$ is positive and significant at the 5\% level, indicating that significant spatial spillover features exist on regional carbon emissions. The regions with severe carbon emissions are often integrated, which is similar to the results of the spatial agglomeration analysis of carbon emissions in Fig. 3. The estimated coefficient of $W^{*} \operatorname{lnrc}$ is significant at the level of $10 \%$, suggesting that regional corruption also bears spatial spillover characteristics. It can be inferred from the estimated coefficients of $\operatorname{lnrc}, \ln ^{2} \mathrm{rc}$, and $\ln ^{3} \mathrm{rc}$ that the effect of regional corruption on carbon emissions initially intensifies, and then declines, and then finally rises again. Although not statistically significant, the results show that the link between regional corruption and carbon emissions is more complicated than a linear function.

In order to further explore the direct and indirect effects of various variables on carbon emissions, this study decomposes the regression results, as shown in Table 6. By utilizing the same methods as LeSage and Pace (2010) and Elhorst (2003), the direct, indirect, and total effects were obtained for each explanatory variable. Table 6 reports the direct, indirect, and total effects of regional corruption on carbon emissions.

(1) There is an indistinctive $N$-shaped relationship between regional corruption and carbon emissions. The estimated coefficients for the linear and cubic terms are positive, 
Fig. 1 The trend of Moran's I-values for regional corruption and carbon emissions in China from 2002 to 2017

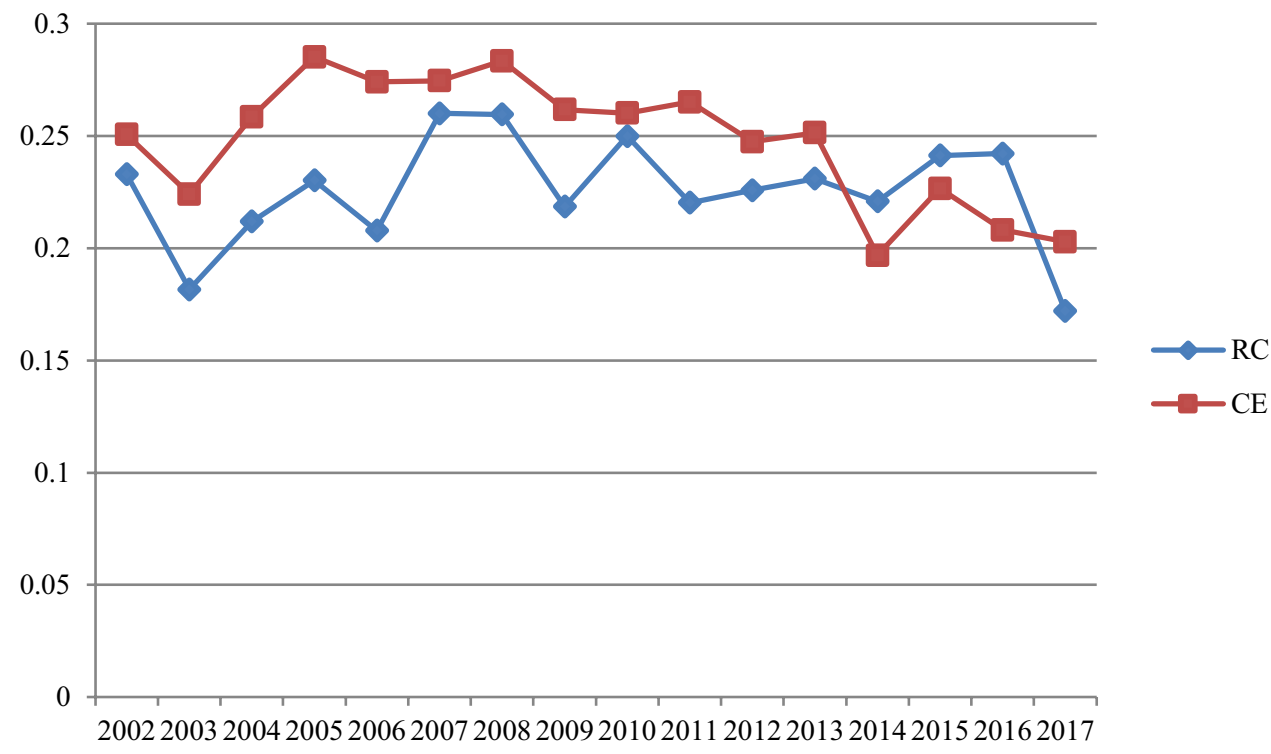

2002
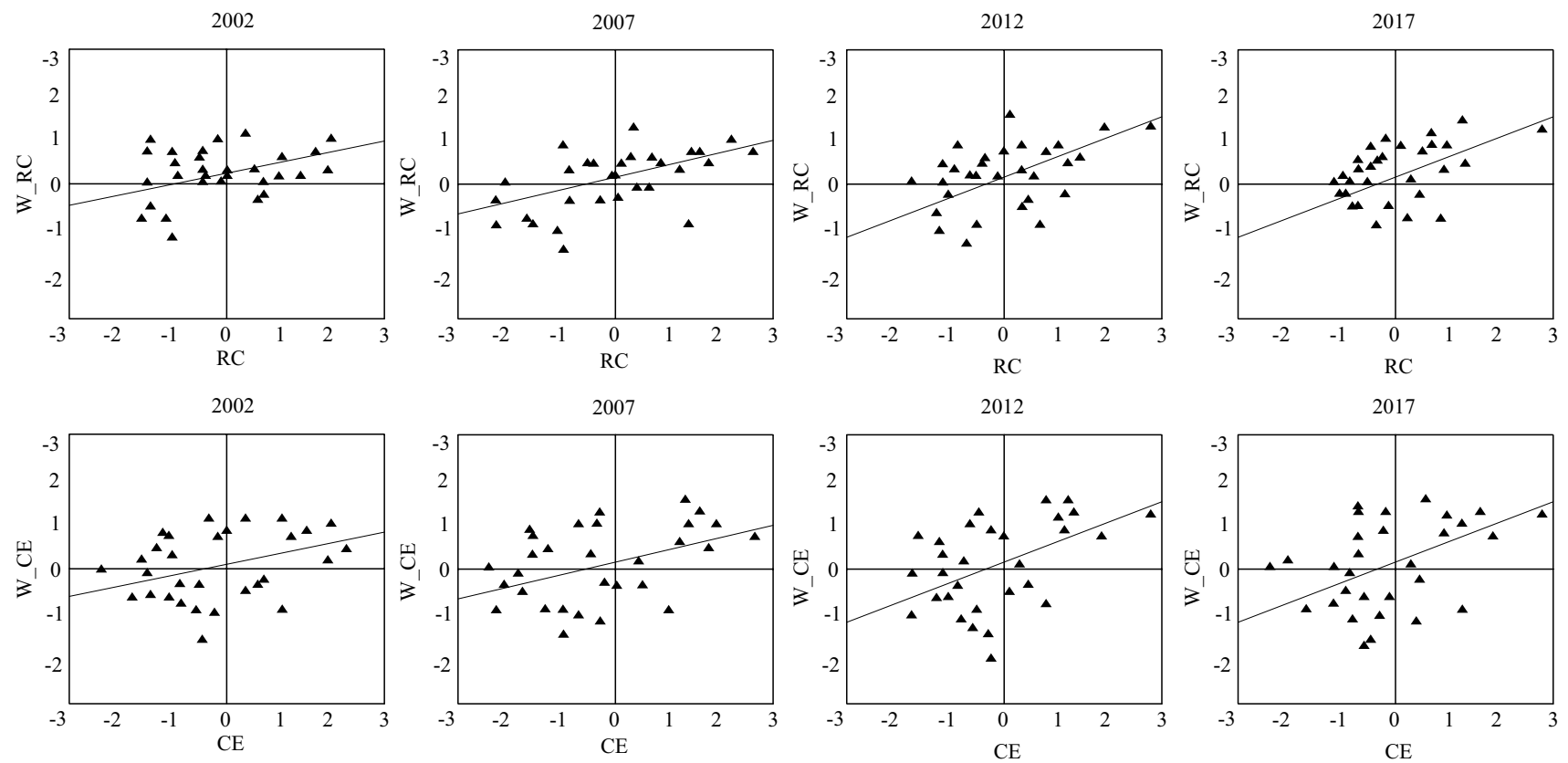

Fig. 2 Moran scatterplots of regional corruption and carbon emissions in China

Table 4 Comparative results of SDM Model, SAR Model, and SEM Model

\begin{tabular}{lllll}
\hline Model comparison & Wald_spatial_lag & prob_spatial_lag & LR_spatial_lag & prob_spatial_lag \\
\hline SDM versus SLM & 20.7498 & $5.2336 \mathrm{e}-06$ & 19.5362 & 0.0067 \\
SDM versus SEM & 14.9886 & 0.0361 & 15.2724 & 0.0327 \\
\hline
\end{tabular}

while the quadratic term is negative, none of which were found to be significant. This means that regional corruption tends to firstly aggravate carbon emissions, which then contributes to emission reduction, and then finally returns to increasing carbon emissions. The link between corruption and regional carbon emissions is not a simple linear relationship, which can partly explain the dynamic non-linear relationship between the two parameters (Li and Liu 2013a; Zhang et al. 2016). Regional corruption may play a positive or negative role in regional carbon governance. On the one 
Table 5 Regression results of regional corruption on carbon emissions based on spatial Durbin model

\begin{tabular}{|c|c|c|c|c|}
\hline Variables & NFE & SFE & TFE & STFE \\
\hline intercept & -0.8093 & & & \\
\hline lnce $_{-1}$ & $0.9345 * * *$ & $0.6585 * * *$ & $0.9167 * * *$ & $0.6472 * * *$ \\
\hline $\operatorname{lnrc}$ & 1.0721 & -0.2598 & 0.8103 & -0.3021 \\
\hline $\ln ^{2} \mathrm{rc}$ & -0.1700 & 0.0395 & -0.1341 & 0.0501 \\
\hline $\ln ^{3} \mathrm{rc}$ & 0.0086 & -0.0023 & 0.0073 & -0.0028 \\
\hline lner & $0.0180 *$ & 0.0116 & $0.02261 *$ & 0.0119 \\
\hline $\operatorname{lngdp}$ & $-0.0520 * *$ & $0.1172 * *$ & -0.0196 & $0.1168 * *$ \\
\hline $\operatorname{lnfdi}$ & $0.0147 * *$ & -0.0043 & 0.0064 & -0.0031 \\
\hline $\operatorname{lnis}$ & $0.04497 *$ & $0.0939 * *$ & 0.0237 & $0.0780 *$ \\
\hline lniece & $0.05927 * * *$ & $0.1470 * * *$ & $0.0497 * * *$ & $0.1278 * * *$ \\
\hline lnisde & $0.0286^{* * *}$ & $0.0389 * * *$ & $0.0476 * * *$ & $0.0447 * * *$ \\
\hline$W^{*}$ Ince $_{-1}$ & $-0.1332 * *$ & -0.0218 & -0.0212 & 0.0329 \\
\hline$W^{*} \operatorname{lnrc}$ & $0.1759 *$ & $3.6656^{*}$ & -1.7609 & 5.0360 \\
\hline$W^{*} \ln ^{2} \mathrm{rc}$ & $0.0087 *$ & $-0.4998^{*}$ & 0.2449 & -0.7117 \\
\hline$W^{*} \ln ^{3} \mathrm{rc}$ & 0.0003 & 0.0226 & -0.0110 & 0.0341 \\
\hline$W^{*} \operatorname{lner}$ & -0.0079 & 0.0060 & -0.0084 & 0.0029 \\
\hline$W^{*} \operatorname{lngdp}$ & -0.0185 & -0.0502 & 0.0786 & -0.1125 \\
\hline$W^{*} \operatorname{lnfdi}$ & 0.0065 & $-0.0606^{* * *}$ & -0.0075 & $-0.0532 * * *$ \\
\hline$W^{*} \operatorname{lnis}$ & 0.0299 & 0.0683 & -0.0348 & 0.0450 \\
\hline$W^{*}$ Iniece & $-0.0480 * *$ & -0.0131 & $-0.0631 * * *$ & -0.0457 \\
\hline$W^{*}$ Inisde & -0.0157 & $-0.0374 * *$ & $0.0426^{*}$ & -0.0092 \\
\hline$\rho$ & $0.1490 * *$ & $0.1130^{*}$ & -0.0280 & 0.0015 \\
\hline $\begin{array}{l}\text { Adjusted } \\
R^{2}\end{array}$ & 0.9882 & 0.9525 & 0.9874 & 0.7392 \\
\hline $\begin{array}{l}\text { Log-like- } \\
\text { lihood }\end{array}$ & 592.6488 & 559.6031 & 515.2007 & 576.4289 \\
\hline
\end{tabular}

Significance: $* P<0.1, * * P<0.05, * * * P<0.01$

hand, corruption helps companies avoid inefficient administrative controls on carbon emissions, which in turn improves the efficiency of resource allocation, thus contributing to environmental pollution control (Jin and Wu 2014). On the other hand, corruption leads to rent-seeking behavior, which can reduce the strength and enforcement capacity of government environmental regulation, thus weakening the effectiveness of government carbon governance (Yu 2019).

Meanwhile, the spatial spillover effect of regional corruption affecting carbon emissions is not significant. The estimated coefficients of the direct and indirect effects of corruption on carbon emissions from Table 6 do not pass the significance test, indicating that corruption in the region does not have a significant impact on carbon emissions in the surrounding areas. From the spatial correlation analysis, we found corruption has a positive impact on the level of corruption in the surrounding area, indicating that when the level of corruption in the region rises, corruption in the surrounding area increases as well. At the same time, carbon emissions also exhibit similar characteristics; as the carbon emissions in a region rise, the carbon emissions in the surrounding areas also increase. However, an increase in the level of corruption in the region does not lead to an increase in the level of carbon emissions in the surrounding area.

The reasons for the non-significant impact of regional corruption on carbon emissions may lie in the following aspects. First, possessing the concealment feature, corruption may encourage the rise in pollution levels by reducing the effectiveness of the implementation of environmental regulations and policies, leading to the non-significant direct effect on carbon emissions (Que and Lv 2015; Yu 2019). Second, there are a large number of informal and hidden economies in China. The impact of regional corruption on the Chinese economy may mainly be manifested through the informal and hidden economies, which then affects the environment and carbon emissions (Que and Lv 2015; Yu 2019). It would be hard to identify the impact of the hidden economy on the environment, which leads to the underestimation of the effect of regional corruption on carbon emissions (Wang and Shao 2019).

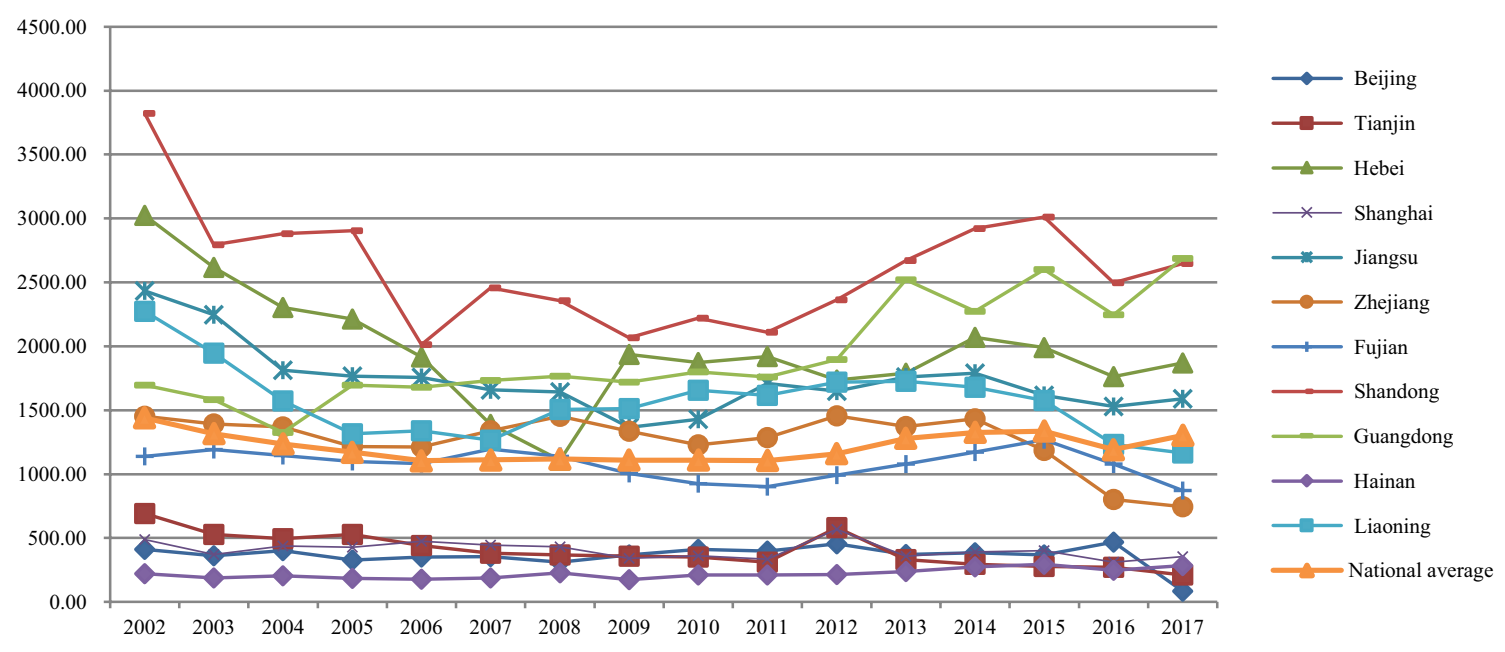

Fig. 3 Trends of regional corruption in eastern regions during 2002-2017 
Table 6 The total effects, indirect effects, and direct effects of regional corruption on carbon emissions

\begin{tabular}{lccc}
\hline Variable & Direct effect & Indirect effect & Total effect \\
\hline lnce ${ }_{-1}$ & $0.9345^{* * *}$ & 0.0072 & $0.9418^{* * *}$ \\
lnrc & 1.0453 & 0.0515 & 1.0968 \\
$\ln ^{2} \mathrm{rc}$ & -0.1660 & -0.0293 & -0.1953 \\
$\ln ^{3} \mathrm{rc}$ & 0.0086 & 0.0023 & 0.0110 \\
$\operatorname{lner}$ & $0.0174^{*}$ & -0.0066 & 0.0108 \\
$\operatorname{lngdp}$ & $-0.0523^{*}$ & -0.0298 & $-0.0821^{* *}$ \\
lnfdi & $0.0152^{* *}$ & 0.0100 & $0.0251^{*}$ \\
lnis & $0.0470^{*}$ & 0.0417 & $0.0886^{*}$ \\
lniece & $0.0586^{* * *}$ & $-0.0442^{*}$ & 0.0144 \\
lnisde & $0.0280^{* * *}$ & -0.0139 & 0.0141 \\
\hline
\end{tabular}

Significance: $* P<0.1, * * P<0.05, * * * P<0.01$

(2) The impact of other control variables on carbon emissions. Carbon emissions have notable spatial lag characteristics. Carbon emissions in the lag 1 phase could have affected the current phase. The total and direct effects are significantly positive, indicating that regional carbon emissions of the previous period directly affect carbon levels of the current period. The higher the previous carbon emission, the higher the current carbon emission. Meanwhile, the indirect effect is indistinctive, suggesting that previous carbon emissions in one region do not impact the current carbon emissions of its nearby areas significantly. Environmental regulation contributes directly and significantly to carbon emissions in the region, but the spatial spillover benefits of environmental regulation affecting carbon emissions are not significant. This means that environmental regulation mainly has a direct effect on carbon control in the region, while the indirect effect on carbon control in the surrounding area is not significant. This result supports the views of Gain (2012) and Allaire and Brown (2016). The level of economic development favors carbon control directly, but the spillover effect of the level of economic development on carbon emissions is not significant. FDI and industrial structure significantly exacerbate carbon emissions in the region, but the spillover effect is not significant. This finding suggests that FDI and industrial structure have a small impact on carbon control in the surrounding area. Laboraverage energy consumption (lnlaec) has a positive direct effect and a negative indirect effect on carbon emissions, while the total effect is not significant. Labor-average energy consumption aggravates carbon emissions in one region and then reduces carbon emissions in the surrounding regions. This parameter has a significant spillover effect on carbon emissions to the surrounding areas. Industrial solid waste directly intensifies carbon emissions in the region, while its
Table 7 Spatial effects of regional corruption and carbon emissions in the eastern region

\begin{tabular}{lccc}
\hline Variable & Direct effect & Indirect effect & Total effect \\
\hline lnce ${ }_{-1}$ & $0.8752^{* * *}$ & 0.0427 & $0.9179 * * *$ \\
lnrc & 0.1256 & -4.9796 & -4.8540 \\
$\ln 2 \mathrm{rc}$ & -0.0571 & 0.7257 & 0.6686 \\
$\ln 3 \mathrm{rc}$ & 0.0051 & -0.0347 & -0.0296 \\
lner & 0.0074 & -0.0442 & -0.0367 \\
lngdp & 0.0233 & -0.0601 & -0.0369 \\
lnfdi & 0.0135 & 0.0617 & 0.0752 \\
lnis & $0.1148^{*}$ & 0.0847 & 0.1995 \\
lniece & 0.0115 & 0.0795 & 0.0910 \\
lnisde & 0.0227 & -0.0307 & -0.0080 \\
$\rho$ & $0.0500^{\mathrm{a}}$ & & \\
Adjusted $R^{2}$ & 0.9875 & & \\
Log-likelihood & 151.0174 & & \\
\hline
\end{tabular}

Significance: $* P<0.1, * * P<0.05, * * * P<0.01$

Significant only at the $20 \%$ level

Table 8 Spatial effects of regional corruption and carbon emissions in the central region

\begin{tabular}{lccc}
\hline Variable & Direct effect & Indirect effect & Total effect \\
\hline lnce $_{-1}$ & $0.8817 * * *$ & 0.0366 & $0.9183^{* * *}$ \\
$\operatorname{lnrc}$ & 9.9447 & 14.4225 & $24.3672^{*}$ \\
$\ln ^{2} \mathrm{rc}$ & -1.3883 & -2.0505 & $-3.4388^{*}$ \\
$\ln ^{3} \mathrm{rc}$ & 0.0645 & 0.0967 & $0.1612^{*}$ \\
$\operatorname{lner}$ & -0.0038 & 0.0267 & $0.0229^{*}$ \\
$\operatorname{lngdp}$ & -0.0309 & -0.0330 & -0.0638 \\
$\operatorname{lnfdi}$ & 0.0088 & -0.0079 & 0.0009 \\
$\operatorname{lnis}$ & 0.0252 & 0.0452 & 0.0704 \\
$\operatorname{lniece}$ & 0.0488 & -0.0306 & 0.0181 \\
$\operatorname{lnisde}$ & $0.0579 * * *$ & $-0.0638^{* * *}$ & -0.0059 \\
$\rho$ & $-0.2361 * * *$ & & \\
Adjusted $R^{2}$ & 0.9896 & & \\
Log-likelihood & & 128.2200 & \\
\hline
\end{tabular}

Significance: $* P<0.1, * * P<0.05, * * * P<0.01$

impact on carbon emissions in the surrounding area is not significant and has no spatial spillover effect.

\section{Regional differences in the impact of corruption on carbon emissions}

Given that the impact of regional corruption on carbon emissions is not significant, this study attempts to explain the reasons from two aspects: regional heterogeneity and period difference. Based on the Chinese administrative divisions, the 30 selected provinces are divided into 
Table 9 Spatial effects of regional corruption and carbon emissions in western regions

\begin{tabular}{llcc}
\hline Variable & Direct effect & Indirect effect & Total effect \\
\hline lnce ${ }_{-1}$ & $0.8975 * * *$ & -0.0166 & $0.8809 * * *$ \\
lnrc & -0.1558 & 0.2601 & 0.1043 \\
$\ln ^{2} \mathrm{rc}$ & 0.0690 & 0.0530 & 0.1220 \\
$\ln ^{3} \mathrm{rc}$ & -0.0060 & -0.0077 & -0.0138 \\
lner & $0.0379^{* *}$ & -0.0375 & 0.0005 \\
lngdp & $-0.1311^{* * *}$ & 0.0810 & -0.0501 \\
lnfdi & 0.0166 & 0.0090 & 0.0256 \\
lnis & $0.1377^{*}$ & -0.1195 & 0.0181 \\
lniece & $0.0593^{* *}$ & -0.0322 & 0.0271 \\
lnisde & $0.0550^{* *}$ & -0.0031 & 0.0519 \\
$\rho$ & $-0.2361^{* *}$ & & \\
Adjusted $R^{2}$ & 0.9894 & & \\
Log-likelihood & 123.0000 & & \\
\hline
\end{tabular}

Significance: $* P<0.1, * * P<0.05, * * * P<0.01$

central, eastern, and western regions. ${ }^{1}$ Tables 7,8 , and 9 show the impact of regional corruption on carbon emissions in eastern, central, and western regions, respectively.

In the eastern region, there is an $N$-type relationship between regional corruption and carbon emissions but is not statistically significant. Neither the direct nor the spillover effects of regional corruption on carbon emissions were found to be significant. As can be seen from Table 7, the direct effect, the indirect effect, and the total effect coefficients of regional corruption were not significant in the eastern region, indicating that regional corruption has no noticeable impact on carbon emissions in the region and the surrounding areas. At the same time, the value of $\rho$ is only significant at the $20 \%$ level, revealing that the spatial spillover characteristic of carbon emissions in the eastern region is not very prominent.

As shown in Fig. 3, the trend in corruption for the eastern region during 2002-2017 shows 5 of the 11 provinces has lower corruption level than the national average, while the other six regions exceed the national average. This means the integral level of the eastern region is consistent with the national average level. Compared with highly developed economies, the corruption level in the eastern region is not too high, and thus has no significant impact

\footnotetext{
$\overline{1}$ The eastern region includes 11 regions, namely Beijing, Tianjin, Hebei, Liaoning, Shanghai, Jiangsu, Zhejiang, Fujian, Shandong, Guangdong, and Hainan province. The central region consists of eight regions: Shanxi, Jilin, Heilongjiang, Anhui, Jiangxi, Henan, Hubei, and Hunan province. Eleven regions compose the western region: Chongqing, Sichuan, Guizhou, Yunnan, Shaanxi, Gansu, Qinghai, Ningxia, Xinjiang, Inner Mongolia, and Guangxi province.
}

on regional carbon emissions and environmental pollution. As relatively developed regions, local governments in the eastern region attach great importance to the coordinated development between economic development and environmental protection. They prioritize having the government image of being honest and upright and put considerable effort into anti-corruption strategies. These measures help make the impact of corruption on environmental quality and carbon emissions indistinctive.

Overall, corruption has a significant impact on carbon emissions in the central region. Specifically, there exists a significant $\mathrm{N}$-shaped link between regional corruption and carbon emissions. As corruption deteriorates, the regional carbon emission level initially ascends, then decreases, and finally rises again. This means that at the initial stage, it is the economic development that receives the most attention from local governments, rather than corruption and environmental problems associated with economic development. Thus, corruption exacerbates regional carbon emissions. When the economy reaches a particular level, and corruption increases rapidly, local governments start to take regional corruption seriously and launch more anti-corruption campaigns. Corruption thus reduces local carbon emissions. Faced with the bottleneck in economic transitioning and upgrading, local governments in the central region then start to concentrate again on economic development and pays less attention to anti-corruption, leading to the increase in local corruption levels and higher carbon emissions ( $\mathrm{Li}$ and $\mathrm{Liu}$ 2013a, b). The direct and indirect effects of regional corruption on carbon emissions are not significant, and the spillover effects of regional corruption on carbon emissions are also not significant.

As shown in Fig. 4, in the central region, six of its eight provinces have higher corruption levels than the national average, while the other two are lower. From an integral perspective, the corruption level in the central region is much higher than the national average. As a result, corruption can affect regional carbon emissions and environmental pollution significantly. Inland location, limited economic development level, and large gaps in regional income all contribute to the high levels of corruption in the regions, which then deteriorate the regional environmental quality (Lawson 2012).

As for the western region, the $N$-type relationship between regional corruption and carbon emissions is not significant. The total effects, indirect effects, and direct effects of regional corruption on carbon emissions are all indistinctive, indicating that neither the direct nor the spillover effects of regional corruption on carbon emissions are significant in the western region. As shown in Fig. 5, eight out of the 11 provinces have lower corruption levels than the national average. On the whole, the corruption level in the western region is lower than the national average. Thus, corruption 


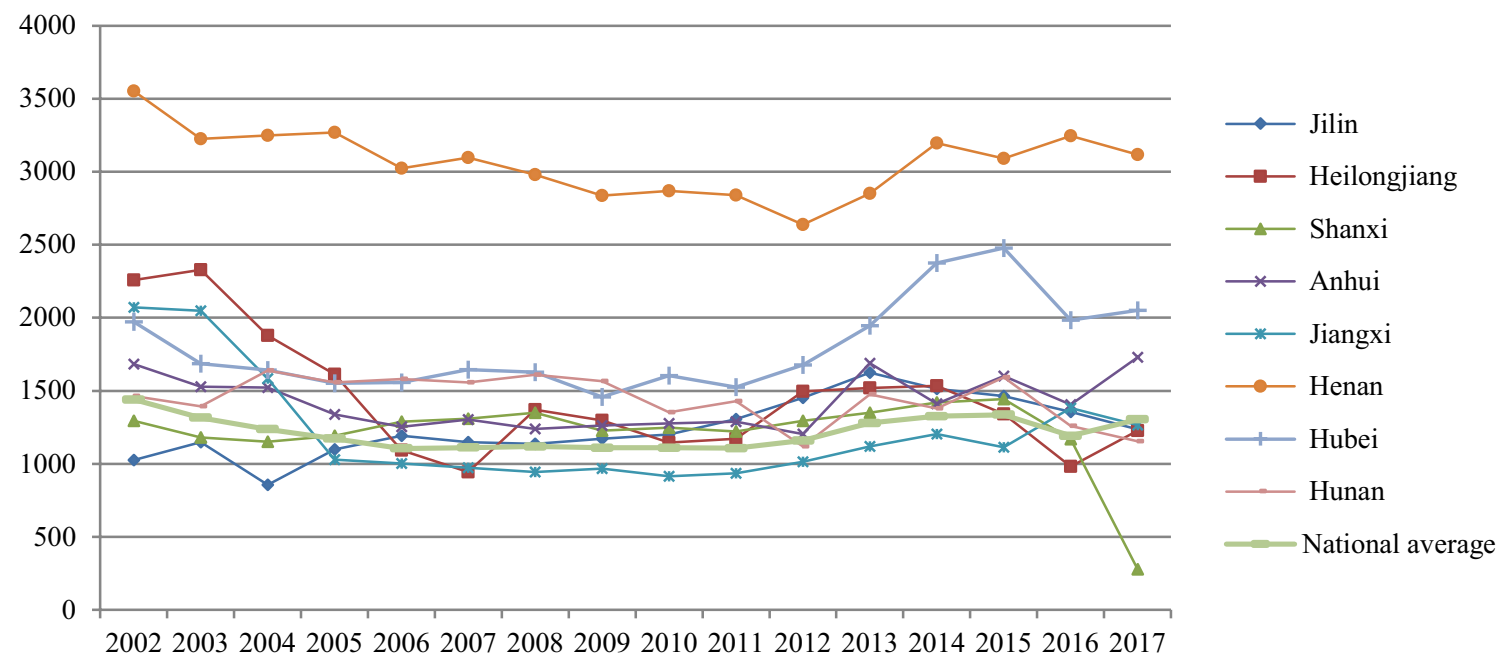

Fig. 4 Regional corruption trend in central regions during 2002-2007

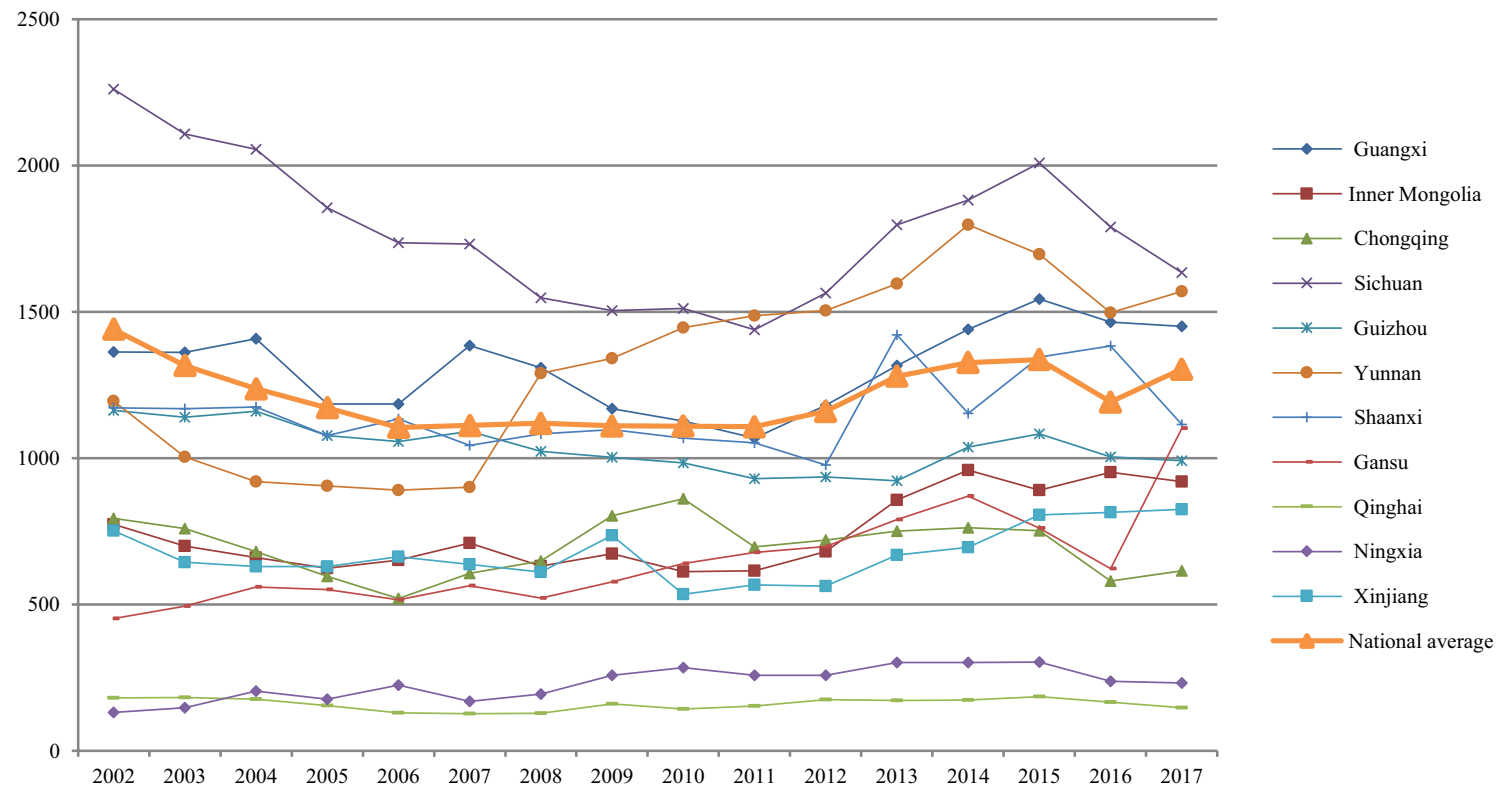

Fig. 5 Regional corruption trend in Western Regions during 2002-2017

exerts an insignificant influence on regional carbon emissions and environmental pollution. In the western region, as the economic development level is relatively low, so is the corruption level, leaving its impact on the environment indistinctive (Welsch 2004; Cole 2007).

In summary, there exists pronounced regional heterogeneity in the impact of regional corruption on carbon emissions. Having high corruption areas in China, the corruption and carbon emissions in the central region show a visible $N$-shaped link. And while this relationship may also occur for the eastern and western regions, the link is fuzzy and indistinct in these areas. This difference in the three regions may be due to the differences in the level of corruption, economic development, and environmental governance awareness in the three regions.

\section{Period differences in the impact of corruption on carbon emissions}

To further explore the impact of regional corruption on carbon emissions, this paper analyzes this impact at different time stages. The sample period is divided into two stages: the earlier stage (2002-2009) and the later stage 
Table 10 Period difference in spatial effects of regional corruption and carbon emissions in China

\begin{tabular}{|c|c|c|c|c|c|c|}
\hline \multirow[t]{2}{*}{ Variable } & \multicolumn{3}{|l|}{ 2002-2009 } & \multicolumn{3}{|l|}{ 2010-2017 } \\
\hline & Direct effect & Indirect effect & Total effect & Direct effect & Indirect effect & Total effect \\
\hline lnce $_{-1}$ & $0.8605 * * *$ & $-0.1397 * *$ & $0.7207 * * *$ & $0.9718 * * *$ & $0.1058 * *$ & $1.0775^{* * *}$ \\
\hline $\operatorname{lnrc}$ & 0.2682 & -1.2476 & -0.9794 & $3.6444 *$ & 7.3692 & 11.0136 \\
\hline $\ln ^{2} \mathrm{rc}$ & -0.0523 & 0.1396 & 0.0873 & $-0.5492 *$ & -1.1586 & -1.7079 \\
\hline $\ln ^{3} \mathrm{rc}$ & 0.0032 & -0.0045 & -0.0013 & $0.0272 *$ & 0.0596 & 0.0868 \\
\hline lner & $0.0552 * * *$ & 0.0124 & $0.0676^{* *}$ & -0.0198 & -0.0562 & $-0.0761 *$ \\
\hline lngdp & -0.0417 & $0.1269 * *$ & 0.0852 & -0.0231 & -0.0321 & -0.0551 \\
\hline $\operatorname{lnfdi}$ & $0.0159 *$ & -0.0146 & 0.0012 & 0.0070 & -0.0009 & 0.0061 \\
\hline $\operatorname{lnis}$ & 0.0229 & 0.0098 & 0.0327 & $0.0751^{*}$ & 0.0615 & 0.1366 \\
\hline Iniece & $0.0690 * * *$ & $-0.0848 * *$ & -0.0158 & 0.0355 & $-0.0705^{*} *$ & -0.0350 \\
\hline lnisde & $0.0702 * * *$ & $0.1085 * * *$ & $0.1787 * * *$ & 0.0221 & $-0.0487 * * *$ & -0.0266 \\
\hline$\rho$ & $-0.0320^{*}$ & & & $0.1359 *$ & & \\
\hline Adjusted $R^{2}$ & 0.9905 & & & 0.9851 & & \\
\hline Log-likelihood & 273.2562 & & & 246.6823 & & \\
\hline
\end{tabular}

Significance: $* P<0.1,{ }^{*} P<0.05, * * * P<0.01$
(2010-2017). Table 10 reports the empirical results for the different time stages.

As shown in Table 10, the effect of regional corruption on carbon emissions varies with time. In 2002-2009, the direct, indirect, and total effects were all insignificant, while during 2010-2017, the direct effect of regional corruption on carbon emissions becomes significant and exhibits an $\mathrm{N}$-shaped link. None of the estimated coefficients for the three effects passed the significance test in the early stage, indicating that neither the direct nor the spillover effects of regional corruption on carbon emissions are significant. In the later stage, the total effect and indirect effect of regional corruption on carbon emissions are still not significant, but the direct effect is significant at the $10 \%$ level, and an obvious $\mathrm{N}$-shaped relationship is formed between the two. This temporal variation is largely due to the following aspects. First, corruption has a certain cumulative effect. At relatively low levels and over a short period, corruption has little impact on regional carbon emissions and environmental quality (Oliva 2015). Second, the influence of corruption on carbon emissions and the environment may exhibit some lag effect, and the influence of corruption only becomes more evident in the later stage (Hassaballa 2015).

\section{Conclusions and policy recommendations}

Based on the panel data of 30 provinces in China from 2002 to 2017 , this paper utilized the spatial Durbin model to systematically analyze the impact of regional corruption on carbon emissions. The main results of the study are as follows:
1. There is an indistinctive $N$-shaped relationship between regional corruption and carbon emissions at the national level. Regional corruption initially aggravates carbon emissions, then contributes to emission reduction, and then finally returns to increasing carbon emissions. However, this effect is not statistically significant. This finding suggests that there may be a non-linear dynamic relationship between regional corruption and carbon emissions and that the role of regional corruption on regional carbon emissions is twofold. Regional corruption can exacerbate or inhibit regional carbon emissions. Regional corruption can help bypass ineffective government regulations and increase the efficiency of corporate carbon governance. However, by undermining the enforcement of environmental regulations, corruption may consequently exacerbate regional carbon emissions.

2. Pronounced regional heterogeneity exists in the influence of corruption on carbon emissions. Regional corruption and carbon emissions show a significant $\mathrm{N}$-shaped dynamic relationship in the central region, while in the eastern and western regions, the relationship is not significant. This difference may be due to the disparities in the level of corruption, economic development, and environmental governance awareness in these regions.

3. The impact of regional corruption on carbon emissions varies with time. During 2002-2009, the effect of regional corruption on carbon emissions is insignificant in terms of the direct, indirect, and total effects. For 2010-2017, the direct effect became significant, and an apparent $N$-shaped relationship formed between regional corruption and carbon emissions. This suggests that 
there is a dynamic and changing relationship between these two variables.

Accordingly, several policy recommendations arising from the research findings can be proposed. First, corruption is a double-edged sword. Local governments should be able to identify when regional corruption plays a positive role in carbon emission governance and when it plays a negative role. Second, different countermeasures against corruption and carbon emissions should be implemented for different regions, particularly in those that focused on strengthening corruption governance in the central region. Third, the governance of the informal and shadow economies should be further strengthened and standardized in order to avoid underestimating the influence of corruption on regional carbon emissions.

\section{Limitations and improvements}

The limitations of this paper are mainly in the following aspects. First, due to the concealment of regional corruption and limitations in data availability, the indicators measuring corruption are limited and can be further improved. Future research can use and develop different indicators to provide a more comprehensive picture of regional corruption levels. More data can be collected from government corruption cases, the efficiency of using government funds, and civil servants' inactivity. With the development of information technology, the use of big data methods for collecting corruption data can be further explored.

Also, this paper analyzes the impact of corruption on carbon emissions, mainly from the perspective of governance. Regional corruption is only one factor that can affect regional carbon governance. Carbon governance depends not only on the quality of government systems but is also influenced by the level of economic development and technology. In addition, the uncertainty of the external environment and major emergencies (such as the coronavirus) can affect the strength and effectiveness of carbon governance. Thus, the impact of institutional quality, government policies, economic aspects, and the environment on carbon governance could be considered in future studies for a more comprehensive analysis. At the same time, further evaluation can be carried out to explore how the interaction of various factors affects carbon governance.

Funding This study has been supported by the National Social Science Foundation of China (No. 18CJY020).

\section{Compliance with ethical standards}

Conflict of interest The authors declare no conflict of interest.

\section{References}

Akhbari R, Nejati M (2019) The effect of corruption on carbon emissions in developed and developing countries: empirical investigation of a claim. Heliyon 5:1-9

Allaire M, Brown SPA (2016) The green paradox of U.S. Biofuel subsidies: impact on greenhouse gas emissions. Econ Energy Environ Policy 4:83-101

Anselin L (1995) Local indicators of spatial association-LISA. Geogr Anal 27:93-115

Ben Jabeur S, Sghaier A (2018) The relationship between energy, pollution, economi c growth and corruption: a partial least squares structural equation modeling (PLS-SEM) approach. Econ Bull 38: $1-20$

Chen G (2011) Corruption and income inequality-empirical evidence from China. Nankai Econ Stud 5:113-131

Chen Y (2016) Host country corruption, FDI and environmental pollution. Word Econ Stud 10:125-134

Cole MA (2007) Corruption, income and the environment: an empirical analysis. Ecol Econ 62:637-647

Elhorst JP (2003) Specification and estimation of spatial panel data models. Int Region Sci Rev 2:244-268

Freckleton M, Wright A, Craigwell R (2012) Economic growth, foreign direct investment and corruption in developed and developing countries. J Econ Stud 39:639-652

Gani A (2012) The relationship between good governance and carbon dioxide emissions: evidence from developing economies. J Econ Dev 37:77-94

Goel RK, Herrala R, Mazhar U (2013) Institutional quality and environmental pollution: MENA countries versus the rest of the world. Econ Syst 37:508-521

Hassaballa $H$ (2015) The effect of corruption on carbon dioxide emissions in the Mena region. Eur J Sustain Dev 4:301-312

Jin S, Wu J (2014) Corruption, economic growth and the environmental kuznets curve. Econ Theory Bus Manag 6:4-12

Kazerouni A, Asgharpour H, Aghamohamadi A, Alamdari EZ (2019) Corruption and the environmental kuznets curve in developed and developing countries. J Res Econ Model 10:7-38

Kelly JA, Vollebergh H (2012) Adaptive policy mechanisms for transboundary air pollution regulation: reasons and recommendations. Environ Sci Policy 21:73-83

Lawson RA (2012) Bo Rothstein: the quality of government: corruption, social trust, and inequality in international perspective. Public Choice 150:793-795

Lesage JP, Pace RK (2010) Spatial econometric models. Springer, Berlin, pp 355-376

Li Z, Liu H (2013a) Foreign direct investment, regional corruption and environmental pollution: an empirical study based on threshold effect. Int Trade Issues 7:50-61

Li Z, Liu H (2013b) Does corruption exacerbate environmental pollution in China: A test based on provincial data. J Shanxi Univ Finance Econ 35:1-11

Li B, Hao Y, Chang C (2017) Does an anticorruption campaign deteriorate environmental quality? Evidence from China. Energy Environ 29:1-28

Liao X, Xia E (2015) Why china attracts FDI inflows? A perspective of environmental stringency and the degree of corruptibility. World Econ Study 1:112-119 
Liao X, Dogan E, Baek J (2016) Does corruption matter for the environment? Panel evidence from China. Economics 11:1-20

Liu Y, Feng H (2011) Corruption, efficiency of public spending and long-term economic growth in China. Econ Res J 17-28

Liu C, Xu Y (2017) How does environmental regulations affect haze pollution control? J China Univ Geosci 17:41-53

Lu X, Zhang Y (2011) "Government-social" decentralization and $\mathrm{CO}_{2}$ emission reduction governance in china: an empirical analysis based on provincial panel data. Finance Econ 6:92-100

Masron TA, Subramaniam Y (2018) The environmental Kuznets curve in the presence of corruption in developing countries. Environ Sci Pollut Res 25:12491-12506

Oliva P (2015) Environmental regulations and corruption: automobile emissions in Mexico City. J Polit Econ 123:686-724

Persson A, Bo R, Teorell J (2013) Why anticorruption reforms failsystemic corruption as a collective action problem. Governance $26: 449-471$

Qin M, Liu X, Gong Y (2016) Does sprawling urban space aggravate haze pollution: an empirical analysis from $\mathrm{PM}_{2.5}$ data in China. Finance Trade Econ 11:146-160

Que D, Lv L (2015) Foreign trade, regional corruption and environmental pollution: an empirical study based on provincial dynamic panel data. World Econ Study 1:120-126

Rodriguez C, Galindo Villardon P (2019) Exploring relationships between environmental performance, E-Government and corruption: a multivariate perspective. Sustainability 11:1-16

Sahli I, Ben Rejeb J (2015) The environmental kuznets curve and corruption in the mena region. Proc Soc Behav Sci 195:1648-1657

Shao S, Li X, Cao J (2019) Urbanization promotion and haze pollution governance in China. Econ Res 54:148-165

Wang X, Shao Q (2019) Non-linear effects of heterogeneous environmental regulations on green growth in G20 countries: evidence from panel threshold regression. Sci Total Environ 660:1346-1354

\section{Affiliations}

\section{Yuanhua Yang $^{1} \mathbb{D} \cdot \mathrm{Xi} \mathrm{Yang}^{2} \cdot$ Dengli Tang $^{3}$}

Xi Yang

20181050@gdufe.edu.cn

Dengli Tang

tangdengli_2008@163.com

1 School of Public Administration, Guangdong University of Finance and Economics, 21 Luntou Road, Haizhu District, Guangzhou 510320, China
Wang Z, Danish ZB, Wang B (2018) The moderating role of corruption between economic growth and $\mathrm{CO}_{2}$ emissions: evidence from BRICS economies. Energy 148:506-513

Wang S, Huang Y, Zhou Y (2019a) Spatial spillover effect and driving forces of carbon emission intensity at the city level in China. $\mathrm{J}$ Geogr Sci 29:231-252

Wang S, Yuan Y, Wang H (2019b) Corruption, hidden economy and environmental pollution: a spatial econometric analysis based on China's provincial panel data. Int J Environ Res Public Health 16:2871-2893

Welsch H (2004) Corruption, growth, and the environment: a crosscountry analysis. Environ Dev Econ 9:663-693

World, Bank (1997) World development report:the state in a changing world. World Bank, Washington, DC

Wu H (2015) Carbon emission reduction in China: spatial and temporal pattern, evolution mechanism and policy suggestions-theory and method based on spatial econometrics. Manag World 11:3-10

Yang Y, Niu G, Tang D, Zhu M (2018) Spatial econometric analysis of the effect of government governance on regional emission reduction: evidence from China. Pol J Environ Stud 27:2833-2842

Yang Y, Tang D, Zhang P (2020) Double effects of environmental regulation on carbon emissions in China-empirical research based on spatial econometric model. Discrete Dyn Nat Soc 1:1-12

Yu C (2019) How does corruption affect environmental pollution in China? From the perspective of the informal economy. Chin J Manag Sci 27:140-148

Zhang YJ, Jin Y, Chevallier J, Shen B (2016) The effect of corruption on carbon dioxide emissions in APEC countries: a panel quantile regression analysis. Technol Forecast Soc Change 112:220-227

Publisher's Note Springer Nature remains neutral with regard to jurisdictional claims in published maps and institutional affiliations.

2 School of International Business, Guangdong University of Finance and Economics, Guangzhou 510320, China

3 School of Business Administration, Guangdong University of Finance and Economics, Guangzhou 510320, China 